\title{
Hemşirelik Araştırmalarında Nitel Çalışmaların Önemi
}

The Importance of Qualitative Studies in Nursing Research

\section{Ebru ÖZTÜRK ÇOPUR ${ }^{1}$, Zehra CAN ${ }^{2}$, Hasan Hüseyin ÇAM ${ }^{3}$, Fatma KARASU ${ }^{4}$}

\begin{abstract}
ÖZ
Nitel çalışmalar bütüncül, gerçekçi, doğal olan, deneyimlerden yararlanan, elde edilen bulguları yorumlayan, anlamaya çalışan, analiz eden araştırma yöntemlerinden biridir. Genel olarak sosyal bilimlerde kullanılan ancak sağladığı bilimsel katkılar nedeniyle son yıllarda kullanımı daha da artan nitel araştırmalar, farklı disiplinler tarafindan da benimsenmeye ve kullanılmaya başlanmıştır. Türkiye'de az sayıda yapılan nitel araştırmalar son yıllarda artış göstermekle birlikte sağlık alanında da kullanımı artmaya başlamıștır. Özellikle sağlık alanındaki önemli mesleklerden biri olan hemşirelik mesleği gerek değerleri gerek yaklaşımları nedeniyle nitel araştırmaların yapı taşlarından olan deneyim, iletişim, bütüncül yaklaşım faktörleriyle uyum sağlamakta ve bu alanda yapılan çalışmaların önemli olduğuna dikkat çekilmektedir. Hemşirelikte yapılan nitel araştırmalar verilen hizmetlerin değerlendirilmesi ve bütünlüğünün sağlanmasına, bilgi birikimi oluşturulmasına, kanıta dayalı uygulamalar için farklı bulguların sunulmasına olanak sağlar. Genel olarak hemşirelik mesleğinin gelişmesi, mesleğe yönelik teorilerin oluşturulması ve farklı bir araştırma kültürünün kazanılmasına katkı sağlayan nitel araştırmalar hemşirelik mesleğinde yapılması gerektiği inanılan çalışmalardır. Türkiye'de hemşirelikte nitel çalışmaların daha fazla sayıda yapılmasının hemşirelik mesleğine önemli katkılar sağlayacağ 1 düşünülmektedir. Bu derleme hemşirelik araştırmalarında nitel çalışmaların önemini vurgulamak amacıyla yazılmıştır.
\end{abstract}

Anahtar Kelimeler: Hemşirelik, Hemşirelik Araştırmaları, Nitel Araştırma.

\section{ABSTRACT}

Qualitative studies are one of the research methods that interpret, try to understand, analyze the findings holistic, realistic, natural and obtained using experience. Qualitative research, which is generally used in social sciences but provided reason of the scientific contributions has been begun by used and adopted different disciplines using much increased in there cent disciplines. In Turkey qualitative researches which are few done, although it has increased in recent years has begun increasing used in the in the field of health. Due to its values and approaches, the nursing profession, one of the important professions especially in the field of health, is in harmony with the experience, communication and holistic approach factors, which are the building blocks of qualitative research, and attention is drawn to the importance of the studies in this field. Qualitative research in nursing enables the evaluation and integrity of the services provided, creating knowledge, and presenting different findings for evidence-based practices. Qualitative research that contributes to the development of the nursing profession in general, the creation of theories to ward the profession and in order to the acquisition of a different research culture are the studies believed should be done out in the nursing profession. Qualitative research study of in nursing in Turkey is thought that doing more will make important contributions to the nursing profession. This review was written to emphasize the importance of qualitative studies in nursing research.

Keywords: Nursing, Nursing Research, Qualitative Research.

${ }^{1}$ Dr. Öğr. Üyesi, Ebru ÖZTÜRK ÇOPUR, Halk Sağlığı Hemşireliği Anabilim Dalı, Kilis 7 Aralık Üniversitesi Yusuf Serefoğlu Sağlık Bilimleri Fakültesi, ebruozturkcopur@kilis.edu.tr, ORCID: 0000-0003-1843-3499

${ }^{2}$ Arş. Gör. Zehra CAN, Doğum ve Kadın Hastalıkları Hemşireliği Anabilim Dalı, Kilis 7 Aralık Üniversitesi Yusuf Şerefoğlu Sağlık Bilimleri Fakültesi, zehracan@kilis.edu.tr, ORCID: 0000-0003-4997-3113

${ }^{3}$ Dr. Öğr. Üyesi, Hasan Hüseyin ÇAM, Halk Sağlığı Hemşireliği Anabilim Dalı, Kilis 7 Aralık Üniversitesi Yusuf Şerefoğlu Sağlık Bilimleri Fakültesi, hasanhuseyincam@kilis.edu.tr, ORCID: 0000-0002-1722-4727

${ }^{4}$ Dr. Öğr. Üyesi, Fatma KARASU, Halk Sağlığı Hemşireliği Anabilim Dalı, Kilis 7 Aralık Üniversitesi Yusuf Şerefoğlu Sağlık Bilimleri Fakültesi, fatmakarasu@kilis.edu.tr, ORCID: 0000-0002-7347-0981

\begin{tabular}{lccc} 
İletişim / Corresponding Author: & Zehra CAN & Geliş Tarihi / Received: & 16.06 .2020 \\
e-posta/e-mail: & zehracan@ @ilis.edu.tr & Kabul Tarihi/Accepted: & 04.10 .2020 \\
\hline
\end{tabular} 


\section{GíRiş}

Nitel araştırmalar, bireylerin tecrübe ettikleri bireysel ya da toplumsal olayların temel niteliklerini açıklama, birey üzerindeki algısını dikkate alma, gözlemleme, görüşme ve dokümanları inceleme yöntemlerini kullanarak yürüttüğü çalışmaları açıklayan, yorumlayan ve analiz eden bir araştırma türüdür. ${ }^{1}$ Nitel araştırmalar son 20 yıla kadar daha çok sosyal bilimler alanında kullanılırken, son yıllarda çoklu değiş̧kenler nedeniyle hastalıkların artması, insan sağlığının gelişimsel ve çevresel faktörlerden de etkilendiğinin kabul edilmesiyle birlikte fen ve sağlik bilimlerinde de kullanım oranları ve önemi artmıştır. ${ }^{2}$

Nitel araştırmaların özellikleri incelendiğinde; doğal ortam içerisinde duyarlılık, araştırmacının çalışmada katılımcı rolü, araştırmanın deseninde esneklik, algıların ortaya çıkarılması, tümevarıma dayalı analiz ve bütüncül yaklaşım bulunmaktadır. ${ }^{3,4}$ Nitel araştırma yönteminin yaklaşımları insanların deneyimlerine, davranışlarına, olay, olgu ve süreçlere odaklanır. ${ }^{4} \mathrm{Bu}$ yaklaşımların sağlık alanına getireceği yenilikler ve etkiler hemşirelik alanına da uygunluk göstermektedir. Hem nitel araştırmalarda hem de hemşirelikte bireyler ön planda olup bireylerin diş çevreyi algılamaları, davranışları, diğer bireylerin bu davranışı nasıl yorumladıkları ve bireylerin empati kurmaları her ikisinde de etkilidir. Nicel araştırmalarda daha çok somut veriler göz önünde bulundurulurken nicel araştırmalardan farklı olarak nitel araştırmalarda deneyimler, davranışlar ve soyut yaşam deneyimleri ele alındığından hemşirelik hizmetlerinin bütünlüğünü sağlamada ve hemşirelikte gelişmekte olan hizmetleri değerlendirmede katk1 sağlayabilmektedir. $\mathrm{Bu}$ nedenlerle hemşirelikte nitel araştırmalar önemlidir. ${ }^{4} \mathrm{Bu}$ derlemenin amaci hemşirelik araştırmalarında nitel çalışmaların önemini vurgulamaktır.

\section{Nitel Araştırma Tanımı}

Nitel araştırma, görüşme, gözlemleme ve doküman analiz etme gibi nitel veri toplama yöntemleri kullanılarak olay ve olguların doğal ortamlarında bütüncül ve gerçekçi bir yaklaşımla nitel bir süreçte izlenen araştırma olarak tanımlanmaktadır. ${ }^{5}$ Nitel araştırma insanlara yönelik alg1 ve olayları doğal ortam da ve gerçekçi olarak derinlemesine incelerken, aynı zamanda farklı disiplinleri bütüncül bir yaklaşımla ele alır. ${ }^{4}$ Nitel araştırmalardaki olgu ve olaylar yorumlanırken bireylerin olaylara yüklediği anlam değerlerine yoğunlaşılır. Nitel araștırmalar derinlemesine analiz ve yorumlama özelliğinden dolayı çoğunlukla özneldir, ancak araştırmacı olayları gerçekliğin dişına çıkmadan sunmakla sorumludur. Sadece araştırmacı olgu ve olayları kendine göre yorumlama, anlamlandırma ve analiz etmeye çalışır. ${ }^{6}$ Nitel araştırmalarda olay ve olguların bütün yönleri ve özellikleriyle ele alınması, bireylerin tutum ve eylemlerinin geçtiği olayların incelenmesi, araştırmacının ve çalışmaya katılanların birebir olarak ilişki içerisinde olması, kişilerin alg1 ve tecrübelerini ortaya koyması gibi özellikler problemin ana temalarının ortaya çıkarılmasını sağlar. ${ }^{4-7}$ Nitel araştırmaların süreci incelendiğinde;

- Problemin algilanması ve tanımlanması

- Probleme yönelik belli bir bakış açısı belirlenmesi

- Yapılacak çalışmanın tasarlanması

- Verilerin toplanmas1

- Toplanan verilerin analiz edilmesi

- Analiz edilen verilerin yorumlanması

- Verilerin rapor halinde sunulması şeklindedir. ${ }^{6}$

Nitel araştırma yaklaşımları; durum incelemesi, eylem araştırmaları, fenomenoloji, etnografi, karma yöntem ve gömülü teori olarak karşımıza çıkmaktadır. ${ }^{5,8}$

\section{Durum incelemesi}

Örnek olay incelemesi olarak da adlandırılmaktadır. Tek bir olayı ya da birden fazla olayı derinlemesine incelemektir. Belli 
bir zaman dilimde yaşanan sosyal olaylarda incelenebilmektedir. ${ }^{8}$

\section{Eylem Araştırması}

Uygulayıcının direkt olarak uygulama alanı içerisinde olduğu bireysel veya bir araştırmacı ile birlikte yaptığ 1 , uygulama sürecine yönelik sorunları ortaya çıkarma ya da var olan sorunu anlama ve çözüme kavuşturmaya yönelik veri toplamayı ve analiz etmeyi kapsayan nitel bir araştırma yaklaşımıdır. $^{8}$

\section{Fenomenoloji}

Nitel araştırma yöntemlerinin bir türü olan fenomenoloji aynı zamanda nitel araştırmalarında temelini oluşturmaktadır. Yaşanılan olaylar ve anlamları ile tecrübeler ana temalar arasindadir. Veri toplama aracı görüşme ve gözlemdir. Kişiyi temel alan veri analizi söz konusudur. ${ }^{8}$

\section{Etnografi}

Genel olarak bir toplumun oluşturduğu kültür ana temalar olarak ele alınır. Standart veri toplama araçlarıyla ölçülmesi mümkün değildir. Gözlemleme, tecrübe etme ve algilama ön plandadır. $\mathrm{Bu}$ sebeple araştırmacının araştırma yapacağı yerin kültürünü, toplumunu ve toplumun kültürü nasıl algıladığını iyi bir şekilde bilmesi gerekmektedir. $^{8}$

\section{Karma Yöntem}

Araştırma problemini anlamaya yönelik hem nicel hem de nitel verilerin kullanıldığ 1 bir araştırma türüdür. ${ }^{9}$

\section{Gömülü Teori}

Bir araştırmanın en önemli noktasının kavramsallaştırılmasına yönelik verilerin sistematik bir şekilde toplanması ve analiz edilmesiyle ortaya çıkan nitel araştırma yaklaşımlarından biridir. $^{10} \quad$ Nitel araştırmalarda veri toplama yöntemleri arasında gözlem, görüşme, odak grup ve doküman incelemesi bulunmaktadır., ${ }^{40}$

\section{Nitel Araștırmaların Kullanım Alanları}

Nitel araştırma yöntemleri çeşitli disiplinlerle birlikte güçlü kuramsal temellere dayanır. Başlangıçta nitel araştırmalar sadece sosyoloji ve antropoloji bilimlerinde kullanılsa da 21. yüzyıldaki felsefe ve bilimsel değişimlerle farklı disiplinler tarafından da benimsenen bir araştırma yöntemi olmaya başlamıştır. Psikoloji, felsefe, sosyoloji, antropoloji, dilbilim gibi sosyal bilimler ve sağlık bilimlerindeki çeşitli disiplinler nitel araştırmalara farklı bakış açısı kazandırmanın yanında yöntemlerine de katkı sağlamışlardır. ${ }^{4,11}$ Genel olarak daha çok sosyal bilimlerde kullanılan nitel araştırmalar son yıllarda eğitim, toplum bilimi ve sağlık alanlarında da kullanılmaya başlanmıştır. Sağlık hizmetlerinde daha çok nicel araştırmalar kullanıldığından nitel araştırmaların kullanımı tartışmaya yol açmıştır. ${ }^{10}$ Ancak Dünya Sağlık Örgütü (DSÖ) sağlı hizmetlerinde kanıta dayalı sağlık sistemlerini geliştirmek için kılavuzlarda artık nitel kanitları da kullanmakta ve sağlık sistemi müdahalelerinin etkinliği, farklı müdahale ve sonuçlarının kabul edilebilmesi gibi sorunlara karşılık nitel çalışmalarla elde edilen bulguların bu sorunları ele almasinda yardımcı olabileceğini belirtmiştir. ${ }^{12}$

Sağlık alanlarında nitel çalışmalarda yaklaşımlar, bakım, iletişim gibi konularda insan deneyimlerinden yararlanma, klinik uygulama alanlarındaki sorunları anlamada yararlanmaktadır. ${ }^{13}$ Sağlık alanında nitel çalışmalardan elde edilen bulgular uygulamada kullanılabilecek teorik ve bağlamsal olarak değerlendirme araçlarının gelişimine de katkı sağlar. Ayrıca incelenen olguyu yaşadığı kültür ve ortam bağlamında inceleyerek kültürel anketlerle yeni araştırma araçlarının geliştirilmesine yardımcı olmaktadır. ${ }^{14,15}$ Genel olarak sağlık hizmetlerinde nitel araştırmaların kullanım amaçları;

- Sağlık bakım hizmetlerini iyileştirmek

- Nicel araştırmalarda açıklanamayan problemlerin incelenmesi

- Toplumun sağlık ihtiyacını belirlemek

- Sağlık müdahalelerinin etkinliğini ölçmek

- Hekim-hasta ilişkisinin incelenmesi 
- Sağlık uygulamalarının hasta üzerindeki etkilerinin incelenmesi

- Sağlık hizmetlerinin verimliliğinin ve kalitesinin ölçülmesi

- Sağl1k hizmetinin talebi üzerine hizmet temininin ve kullanımının arasındaki ilişkinin incelenmesi

- Hasta tatmin düzeyini belirlemek

- Sağlık alanında yapılan yeniliklerle ilgili gerekli görüşlerin alınması

- Hasta veya hekim davranışlarının nedenlerini belirleme

- Hem hizmeti sunanlar hem de hastalar açısından önemli noktaları ortaya koymak gibi konulardan oluşur. ${ }^{10,14,15}$

\section{Türkiye'de Nitel Araştırmaların Durumu}

Türkiye'de nicel araştırmalar nitel araştırmalara göre daha yaygındır. Ancak son yıllarda nitel araştırmalarında yaygınlaşmaya başladığı görülmektedir. ${ }^{16}$ Yapılan bazı alanlardaki çalışmalar ise Türkiye'de nitel çalışmaların daha az yapıldığını desteklemektedir. Özellikle Türkiye'de eğitim bilimleri üzerinde yapılan bilimsel çalışmalarda nitel çalışmaların daha az olduğu belirtilmiştir. ${ }^{17-19}$ Ayrıca bilimsel çalışmalarla birlikte Türkiye'de yüksek lisans ve doktora çalışmalarında da nitel çalışmaların daha az yapıldığı ortaya çıkmıştır. Türkiye'de üniversitelerde eğitim denetimi alanında lisansüstü tezleri inceleyen çalışmada \%19,63'ünün nitel çalışmalar olduğu bulunmuştur. ${ }^{20}$ Doktora tezleri üzerinden yapılan başka bir çalışmada ise nitel araştırma yaklaşımlarından durum çalışması $\% 11,3$, eylem araştırması $\% 2,1$, olgu bilim çalışması ise \%1,7 olarak belirlenmiş, bununla birlikte doktora tezlerinde çok az sayıda nitel araştırma modelleri kullanılarak çalışma yapıldığ saptanmıştır. $^{21}$ Aynı zamanda etkin bir araştırma kültürünün oluşmasını sağlayan nitel çalışmaların Türkiye'de az sayıda yapılmasından dolayı bu araştırmaları ilk kez yapan doktora öğrencilerinin çeşitli sorunlar yaşadığı ortaya çıkmıştır. ${ }^{22}$ Türkiye' de sağlık alanında yapılan tezlere yönelik bir çalışma incelendiğinde nicel araştırmaların nitel araştırmalara göre daha fazla sayıda yapıldığı bulunmuştur. $^{23}$ Türkiye'de hemşirelikte yapılan nitel araştırmaların durumuna bakıldığında yapılan nitel çalışmaların çok az sayıda olduğu ancak günümüzde yapılan nitel çalışmaların sayısında artış olduğu saptanmıştır., ${ }^{4,24,25}$

\section{Hemşirelik Araştırmalarında Nitel Çalışmaların Önemi}

Son y1llarda ülkemizde daha fazla sayıda yapılmaya başlanan nitel araştırmalar sağlık alanında da önem kazanmaya başlamıştır. Sağlık alanında önemli hizmet sektörü içerisinde bulunan hemşirelik mesleğindeki yapılan araştırmalar da nitel çalışmalar daha etkin rol almaya başlamıştır. Nitel araştırma yöntemlerinin yapı taşları olan yaşanmış tecrübeler, iletişim, doğallık ve bütüncül olma ilkeleri hemşirelik değerleri ile de uyum göstermektedir. Nitel çalışmalarda bireylerin dış dünya ile ilgili algıları, iletişimleri, bireylerin ne düşündüklerini anlamaya çalışma hemşirelik mesleğinde de bulunduğundan bu alanda yapilan nitel araştırmalar daha da önem kazanmaktadır. Nitel araştırmalar hemşirelikte verilen hizmetlerin bütünlüğünü sağlamada hem de hemşirelikte gelişmekte olan hizmetlerin değerlendirilmesine katkı sağlarken, hemşirelik mesleğinde siklıkla hemşirelik eğitiminde, kritik düşünme becerisinde, toplumu temel alan hizmetlerde ve evde bakım hizmetlerinin değerlendirilmesinde kullanılmaktadır., ${ }^{4,26}$ Nitel çalışmalar hemşirelerin deneyime dayalı teoriler oluşturmasına imkan verir. Hemşirelik ile ilgili sorunları kapsamlı bir şekilde ele alan ve açıklayan en uygun araştırma yöntemlerinden biri olan nitel araştırmalar hemşirelik biliminin ve uygulamasının gelişimine katkıda bulunurken, aynı zamanda niceliksel çalışmaların tasarlanması, uygulanması ve geliştirilmesine de temel oluşturur. Nitel araştırmalar hemşirelikte kanıta dayalı uygulamalar oluşturmak için çok çeşitli bulguların oluşmasına da olanak sağlar. ${ }^{27-29}$ Ayrıca yapılan bir çalışmada nitel araştırmaların hemşirelik öğrencilerine de öğretilmesini ve niteliksel araştırma 
becerisinin kazandırılmasını desteklemekte olup, bu durumun tecrübeli hemşirelerin deneyimleri ve öğrenci hemşirelerle sosyalleşmeyi arttıracağ 1 görüşünü savunmaktadır. ${ }^{30}$ Niteliksel çalışmalar hemşirelik bakımının olduğu her alanda ve bu alanlardan elde edilen bulgularla hemşirelerin bilgi birikimini arttırmasını destekler. Nitel araştırmalar hemşirelik araştırmalarının, hemşirelik teori gelişiminin ve bireye duyarlı hemşirelik müdahalelerinin oluşmasına katkı sağlar. $\mathrm{Bu}$ çalışmaların bireyin bakış açısına, yaşamına etki eden davranışlarına etkileri sebebiyle hemşirelikte yapılması gereken çalışmalar olduğu vurgulanmaktadır. ${ }^{26,31}$ Türkiye'de hemşirelik alanında yapılan nitel çalışmaların sayısı çok azdır. Yapılan bir çalışmada hemşirelik alanında yapılan nitel çalışmaların en çok doğum ve kadın hastalıkları hemşireliği alanında yapıldığı belirtilmiştir. Hemşirelikte nitel çalışmaların az sayıda yapılmasının nedenleri arasinda olarak somut veriler elde edildiği için daha çok nicel çalışmaların kullanılması, lisans ve lisansüstü programlardaki ders sayısının ve niteliğinin yetersizliği, az sayıda yapılan yüksek lisans ve doktora tezlerinin bulunması ve nitel araştırmalardaki etik sorunlardır. Nitel çalışmalar hemşirelikte mesleğin gelişimi, etkin bir araştırma kültürünün oluşumu, mesleğin değerlendirilmesi gibi konularda önemli katkılar sağlamaktadır. ${ }^{4}$

\section{SONUÇ VE ÖNERILER}

Nitel araştırmaların yaklaşımlarından olan deneyimler, iletişim ve bütüncül yaklaşımlar hemşirelik mesleğinin değerleriyle uygundur. Hemşirelikte verilen hizmetlerin kalitesini arttırmada katk1 sağlayan, mesleğin gelişimine etki eden nitel araştırmaların hemşirelikte daha fazla sayıda yapılması gerekmektedir. Hemşirelik mesleğinde daha fazla yapılan nitel çalışmalar sayesinde hemşirelikte teori ve kuramların gelişimi, bireye daha duyarlı hemşirelik uygulamalarının oluşacağı ve kazanılan araștırma kültürünün mesleğe ve kalitesine önemli etkiler sağlayacağı düşünülmektedir.

\section{KAYNAKLAR}

1. Baltacı, A. (2018). "Nitel Araştırmalarda Örnekleme Yöntemleri ve Örnek Hacmi Sorunsalı Üzerine Kavramsal Bir İnceleme.” Bitlis Eren Üniversitesi Sosyal Bilimler Enstitüsü Dergisi, 7 (1), 231-274.

2. Yılmaz, A. (2016)." Hasta Hekim İletişimindeki Problemler ve Bu Problemlere Yönelik Cözüm Önerileri; Nitel Araștırma." Atatürk Üniversitesi Tıp Fakültesi Aile Hekimliği Anabilim Dalı, Uzmanlık Tezi, Erzurum.

3. Yıldırım, A. (1999). "Nitel Araștırma Yöntemlerinin Temel Özellikleri ve Eğitim Araştırmalarındaki Yeri ve Önemi." Eğitim ve Bilim, 23 (112), 7-17.

4. Durmuș, HA. (2016). "Türkiye'de Hemșirelikte Nitel Araştırmaların Durumu." Ege Üniversitesi Hemşirelik Fakültesi Dergisi, 32 (1), 90-96.

5. Karataş, Z. (2015). "Sosyal Bilimlerde Nitel Araștırma Yöntemleri”. Manevi Temelli Sosyal Hizmet Araştırmaları Dergisi, 1 (1), 62-80.

6. Baltacı, A. (2019). "Nitel Araştırma Süreci: Nitel Bir Araştırma Nasil Yapılır?" Ahi Evran Üniversitesi Sosyal Bilimler Enstitüsü Dergisi, 5 (2), 368-388.

7. Özdemir, M. (2010). "Nitel Veri Analizi: Sosyal Bilimlerde Yöntembilim Sorunsalı Üzerine Bir Çalışma.” Eskişehir Osmangazi Üniversitesi Sosyal Bilimler Dergisi, 11 (1), 323343.

8. Ilgar, MZ, Ilgar, SC. (2013). "Nitel Bir Araștırma Deseni Olarak Gömülü Teori (Temellendirilmiş Kuram)." İstanbul Sabahattin Zaim Üniversitesi Sosyal Bilimler Dergisi, 2 (1). 197-247.
9. Creswell, JW, Sözbilir, M. (2017). Karma Yöntem Araştırmalarına Giriş. Ankara: Pegem Akademi.

10. Sönmez, S, İlgün, G. (2018). "Nitel Araştırma Yöntemlerinin Sağlık Hizmetleri Bağlamında İncelenmesi." Balıkesir Üniversitesi Sosyal Bilimler Enstitüsü Dergisi, 21 (40), 375400 .

11. Celik, H, Baykal, NB, Memur, HNK. "Nitel Veri Analizi ve Temel İlkeleri.” Eğitimde Nitel Araştırmalar Dergisi, 8 (1), $379-406$.

12. Lewin, S., Glenton, C. (2018). "Are We Entering a New Era For Qualitative Research? Using Qualitative Evidence To Support Guidance and Guideline Development By The World Health Organization." International Journal For Equity İn Health, 17 (1), 1-5.

13. Khankeh, H, Ranjbar, M, Khorasani-Zavareh, D, ZarghamBoroujeni, A, Johansson, E. (2015). "Challenges İn Conducting Qualitative Research İn Health: A Conceptual Paper.” Iranian Journal Of Nursing And Midwifery Research, 20 (6), 635-641.

14. Luciani, M, Jack, S. M, Campbell, K, Orr, E, Durepos, P, Lin, L, Strachan, P, Di Mauro, S. (2019). "An Introduction to Qualitative Health Research-Un'introduzione Alla Ricerca Sanitaria Qualitativa.” Professioni İnfermieristiche, 72 (1), 6068.

15. Al-Busaidi, ZQ. (2008). "Qualitative Research and İts Uses İn Health Care." Sultan Qaboos University Medical Journal, 8 (1), 11-19.

16. Uzuner, Y. (2015). "A Critical Examination of My Qualitative Research Efforts İn Turkey." Eğitimde Nitel Araștırmalar Dergisi, 3 (3), 44-54. 
17. Güven, E. (2014). "Fen Eğitimi Alanındaki Türkçe Yayımlanmış Nitel Makalelerin İncelenmesi." Journal of European Education, 4 (1), 1-10.

18. Doğan, H, Tok, TN. (2018). “Türkiye'de Eğitim Bilimleri Alanında Yayınlanan Makalelerin İncelenmesi: Eğitim Ve Bilim Dergisi Örneği.” Current Research İn Education, 4 (2), 94-109.

19. Güven, E, Kaplan, Z, Kaplan, Z, Varinlioğlu, S, Varinlioğlu, S, Sungur, K, Hamalosmanoğlu, M, Bozkurt, O. (2014). "Çevre Eğitimi Alanındaki Çalışmaların İncelenmesi: Türkiye'de Mevcut Durum." Necatibey Eğitim Fakültesi Elektronik Fen Ve Matematik Eğitimi Dergisi, 8 (2), 1-18.

20. Ergün, M, Recepoğlu, E, Küçük, ZA, Oğuz, K. (2014,). "Türkiye'deki Üniversitelerde Eğitim Denetimi Alanında Yapılan Lisansüstü Tezlerin Çeşitli Değişkenlere Göre İncelemesi." Kastamonu Eğitim Dergisi, 22 (1), 25-40.

21. Karadă ğ, E. (2010). "Eğitim Bilimleri Doktora Tezlerinde Kullanılan Araştırma Modelleri: Nitelik Düzeyleri ve Analitik Hata Tipleri.” Kuram Ve Uygulamada Eğitim Yönetimi Dergisi, 16 (1), 49-71.

22. Ersoy, A. (2015). "Doktora Öğrencilerinin İlk Nitel Araştırma Deneyimlerinin Günlükler Aracılı̆̆ıly İncelenmesi." Pegem Eğitim ve Öğretim Dergisi, 5 (5), 549-568.

23. İnam, Ö, Koç Tütüncü, S. (2017). “Türkiye'de Sağlık Alanında Toplam Kalite Yönetimi Konusunda Yapılmıs Tez Profillerinin İncelenmesi (2012-2016).” İstanbul Gelişim Üniversitesi Sağlık Bilimleri Dergisi, (2), 109-122.

24. Sahin, G, Buldak, Cİ, Kaya, V, Güvenç, G, İyigün, E. (2020). "Türkiye'de Hemşirelikte Model Kullanılarak Yapılan Lisansüstü Tezlerin İncelenmesi: Sistematik Derleme." Hemşirelik Eğitim ve Araştırma Dergisi, 17 (2), 170-9.

25. Tel, H, Sabancioğulları, S. (2014). "Psikiyatri Hemşireliği Doktora Tezlerinin Özellikleri." Dokuz Eylül Üniversitesi Hemşirelik Fakültesi Elektronik Dergisi, 7 (3), 178-185.

26. Manav, G, Ocakçı, A. (2013). "Hemşirelik Araştırmalarında Niteliksel Çalışmalar: Durum Çalışması Örneği." Cumhuriyet Hemşirelik Dergisi, 2 (1), 26-31.

27. Anthony, S, Jack, S. (2009). "Qualitative Case Study Methodology in Nursing Research: an İntegrative Review." Journal of Advanced Nursing, 65 (6), 1171-1181.

28. Bergdahl, E, Berterö, CM. (2015). "The Myth of İnduction in Qualitative Nursing Research.” Nursing Philosophy, 16 (2), $110-120$

29. Driessnack, M, Sousa, VD, Mendes, IAC. (2007). "An Overview of Research Designs Relevant to Nursing: Part 2: Qualitative Research Designs.” Revista Latino-Americana De Enfermagem, 15 (4), 684-688.

30. Arieli, D, Tamir, B, Man, M. (2015). "Teaching Qualitative Research as a Means of Socialization to Nursing." Nurse Education Today, 35 (6), 795-799.

31. Zucker, D. M. (2001). "Using Case Study Methodology İn Nursing Research.” The Qualitative Report, 6 (2), 1-13. 